\title{
Knowledge, Attitude and Practices (KAP) Regarding Chronic Complications of Diabetes among Patients with Type 2 Diabetes in
} Dhaka

\author{
Kh. Shafiur Rahaman, ${ }^{1}$ Reza Majdzadeh,,${ }^{2,}$ Kourosh Holakouie Naieni, ${ }^{3}$ and Owais Raza ${ }^{4}$ \\ ${ }^{1}$ Khwaja Badrudduja Modern Hospital, Gazipur, Bangladesh \\ ${ }^{2}$ Professor, Department of Epidemiology and Biostatistics, School of Public Health and Knowledge Utilization Research Center, Tehran University of Medical Sciences, Tehran, \\ IR Iran \\ ${ }^{3}$ Professor, Department of Epidemiology and Biostatistics, School of Public health, Tehran University of Medical Sciences, Tehran, IR Iran \\ ${ }^{4} \mathrm{PhD}$ Candidate, Department of Epidemiology and Biostatistics, School of Public health, International Campus, Tehran University of Medical Sciences, Tehran, IR Iran \\ "Corresponding author: Reza Majdzadeh, Professor, Department of Epidemiology and Biostatistics, School of Public Health and Knowledge Utilization Research Center, Tehran \\ University of Medical Sciences, Tehran, IR Iran. Tel: +98-9123067081, E-mail: rezamajd@tums.ac.ir
}

Received 2016 September 29; Accepted 2017 July 02.

\section{Abstract}

Background: To reduce morbidity and mortality, awareness regarding diabetes and its complications is necessary. This study aimed at assessing the level of knowledge, attitude, and practices (KAP) regarding complications of diabetes mellitus among patients with type 2 diabetes in Dhaka, Bangladesh.

Methods: A cross-sectional study was carried out recruiting patients with diabetes from the outpatient department of BIRDEM hospital in Dhaka. Overall, 425 patients with diabetes were enrolled in this study. A pretested questionnaire was filled by the interviewer with face to face interview. Levels of KAP were determined by calculating the scores. Multivarable linear regression was used to determine significant predictors for knowledge, attitude, and practices.

Results: On average, the level of knowledge, attitude, and practices were 9.2 (out of 14), 7.9 (out of 13), and 16.9 (out of 27), respectively. Age and gender were significant predictors of knowledge and attitude. Females had better level of knowledge and attitude compared to males ( $\beta s=0.55$ and 1.24, respectively). Patients with graduate degrees and above compared to illiterates reported significantly greater knowledge and practice $(\beta s=1.27$ and 1.44 , respectively), after adjustments for covariates. Educational program was the most important significant predictor of KAP. Higher duration of diabetes $(\beta=0.07)$ and positive marital status $(\beta=1.21)$ had influenced better practice.

Conclusions: Lack of knowledge, poor attitude, and inadequate practice were found in this surveyed communinty. Level of education and educational program on diabetes were the most significant contributing factors. The current study suggests the need of structured educational programs on diabetes and its complications on a regular basis to assist patients in living a productive life.

Keywords: Health Knowledge, Attitudes, Practice, Diabetes Mellitus, Type 2, Diabetes Complications

\section{Background}

Diabetes is the cardinal cause of death globally $(1,2)$. From a total of 3.7 million deaths linked to blood glucose level in 2012, diabetes was the direct cause of 1.5 million deaths worldwide and additional 2.2 million deaths were caused by increasing risk of cardiovascular and other diseases due to hyperglycemia $(3,4)$. It expected for diabetes to become the 7th leading cause of death by 2030 (4).

In the context of Bangladesh, there was a significant rise in the prevalence of diabetes among adults, in the past few years, indicated by a recent meta-analysis (5). Nowadays, 7.1 million adults are affected by diabetes, and this number is expected to increase to 13.6 million by 2040 (1). Prevalence is higher in urban (8.1\%) populations than ru$\operatorname{ral}(2.3 \%)(6,7)$. Moreover, Bangladesh is among the top ten countries with the highest number of adults with diabetes
(8).

Progression of type 2 DM consequences certain acute and chronic complications in the majority of cases $(9,10)$. The present situation in Bangladesh will lead to consistent rise in the number of people with diabetic complications $(11,12)$. Due to the insidious nature of this disease, many people remain undiagnosed until complications appear (13). Lack of proper care at the early stage of development influences the patient's quality of life, which also thrusts a considerable economic burden (14). The development of chronic complications is influenced by hyperglycemia (15). In almost all high-income countries, diabetes is a leading cause of cardiovascular disease, blindness, kidney failure, and lower limb amputation (8). The risk of dying among people with diabetes is twice than that of people without diabetes (16). Necessary interventions should be put in 
place, otherwise the cost of care for type 2 diabetes mellitus patients will have a negative impact on the health care system, as suggested by experts (17).

Many initiatives have already been taken to educate people with diabetes on how to minimize the complications, the impact is yet to be revealed. This primary particulars can be useful to execute future interventional strategies.

\section{Objectives}

This study was carried out with the aim of determining knowledge, attitude, and practices regarding complications of diabetes among patients with type 2 diabetes in Dhaka, Bangladesh.

\section{Methods}

The study was designed as a questionnaire based, crosssectional analysis. Among all suitable patients, by employing convenient sampling, 425 patients with type 2 diabetes were recruited from the outpatient department of BIRDEM hospital in Dhaka, the capital of Bangladesh, in June 2016. This is the largest tertiary care hospital of the Diabetic Association of Bangladesh, providing facilities particularly for individuals with diabetes, regarding general health and emergency treatments for all illnesses and accidents. The sample included patients with type-2 diabetes older than 18 years attending for follow up or seeking general treatment in medicine outpatient departments except diabetes-related complications (such as diabetic foot, diabetic retinopathy, nephropathy, and neuropathy) with at least 1 year since the initial diagnosis of diabetes (1 year was to assure at least 1 training session on diabetes). Exclusion criteria included the presence of gestational diabetes mellitus, age of younger than 18 years, and being inpatients. Those unable to answer the questionnaire because of dementia, psychosis or profound deafness were excluded from the study.

\subsection{Questionnaire Design}

A pre-tested structured, bilingual questionnaire was developed to investigate key research questions comprised of both open- and close-ended questions. Each participant was interviewed face-to-face by a data collection team. The questionnaire was divided to 6 main categories, including demographic information, socioeconomic information, diabetes history and knowledge, attitude and practicerelated information. Relevant questions were asked from the respondents, such as that of the knowledge module; emphasis was placed to assess the level of knowledge of respondents for complication of diabetes. To assess knowledge, attitude, and practices, 14, 12, and 9 questions were asked, respectively. Medical records were reviewed for recent hemoglobin A1C (HbA1C) levels (within 6 months of the inclusion), retrospectively. Ethical considerations were fulfilled by obtaining verbal consent and maintaining the confidentiality.

\subsection{The KAP Score}

To calculate knowledge, attitude and practices (KAP) score, a scoring system was prepared. Each correct answer was coded as 1 , while each incorrect answer was coded as 0 . In the practice section, components with better practice obtained a higher score up to 5, while respondents with poorer practice received lower scores. The final score for each category was then divided in quartiles. Four categories of knowledge, attitude and practice were outlined according to the score obtained by each respondent.

\subsection{Statistical Analysis}

The collected data was entered in the statistics package for social science (SPSS) version 22 for Windows. All continuous data were expressed as mean $( \pm S D)$, and categorical variables were expressed as numbers and percentages. Descriptive statistics and frequency distributions were used to describe participant characteristics. The respondent's socioeconomic status was calculated by using the principal component analysis (PCA) method according to the patient's fixed assets and employment status. For variables with greater than two categories, one way analysis of variance ANOVA was used to compare means. After univariate and bivariate analysis, variables were entered in the software for multivariable analysis, considering all assumptions to meet the criteria. A forward selection method was applied using $\mathrm{P}$ values of 0.05 and 0.2 for including and excluding the variables from the final model, respectively. For analysis of attitude, the knowledge score was considered as an independent variable and for practice analysis both knowledge and attitude score were considered. Data was checked for the normal distribution of standardized residual plotting, observed cumulative probability, and expected cumulative probability.

\section{Results}

A total number of 425 patients with diabetes were enrolled in the study. Among them, 234 (55.1\%) were males. Number of patients was higher the age group between 26 and 45 years $(n=231 ; 54.4 \%)$. The mean \pm standard deviation (SD) of age of the study participants was $43.45 \pm 11.81$ 
years (range between 21 and 82 years). The majority of the participants ( $\mathrm{n}=190 ; 44.7 \%$ ) were urban habitats.

The mean duration of diabetes was $9.16 \pm 6.03$ years. One hundred and seventy-four (40.9\%) patients had a family history of diabetes. One hundred and sixty-four (38.6\%) participants had attended educational programs on diabetes only once during the disease period. Nearly $60 \%$ of participants reported that a consultation time was provided between 5 to 10 minutes. One hundred and twelve (26.4\%) patients reported that they were using herbal medication beside their regular prescriptions. Details are shown in Table 1.

Only $3.8 \%(n=16)$ of respondents reported that they monitored their blood glucose by themselves and nearly $70 \%(n=297)$ at the hospital. The mean Random Blood Glucose was $11.06 \pm 3.17 \mathrm{mmol} / \mathrm{L}$ (range 4.80 to $19.80 \mathrm{mmol} / \mathrm{L}$ ), noted from the patients guidebook provided by the hospital for routine checkups. Mean HbA1c was $9.73 \pm 2.65 \%$ (range $3.8 \%$ to $16.7 \%$ ). Most of the participants mentioned that the source of their information regarding diabetes and its complications was doctors. The percentage was approximately $64 \%(n=270)$ (Table 2$)$.

Table 2. Sources of Information Among the Survey Respondents $(n=425)$

\begin{tabular}{|lc}
\hline Sources & No. $(\%)$ \\
\hline Physicians & $270(63.5)$ \\
\hline Friends/relatives & $13(3.1)$ \\
\hline Magazines/books & $45(10.6)$ \\
\hline Television/radio & $45(10.6)$ \\
\hline Newspaper & $42(9.9)$ \\
\hline Internet & $10(2.4)$ \\
\hline
\end{tabular}

\subsection{Knowledge Score}

The maximum knowledge score was 14 . The mean score was 9.2 (95\% CI 8.9-9.4) and standard deviation(SD) was \pm 2.11, with a range of 4 to 14 . The study indicated that less than $50 \%$ of participants had poor knowledge regarding diabetic complications ( $n=179 ; 42.1 \%$ ). Nearly $15 \%$ of participants possessed very good knowledge $(n=63 ; 14.8 \%)$.

Approximately $81 \%(n=343)$ of participants agreed that uncontrolled diabetes could cause certain complications. According to the correct answers given by the respondents, eye complication (retinopathy) was least known ( $\mathrm{n}=77$; 18.1\%). Most were known about renal and heart complications. Stroke due to uncontrolled diabetes was also known ( $n=402 ; 94.6 \%$ ). Regarding prevention of diabetic complications, $68 \%(n=289)$ of respondents notified that they knew how to prevent these complications. Details are visualized in Figure 1.

The study indicated that patients with older age had better knowledge $(\mathrm{P} \leq 0.001)$. Females had higher knowledge than males $(\mathrm{P}=0.004)$. Patients living in urban and semi-urban areas $(\mathrm{P}=0.022)$, educated above secondary level $(\mathrm{P} \leq 0.001)$ and working in the government and private sector $(\mathrm{P}=0.018)$ had better knowledge compared to their respective groups. Socioeconomic status of the respondents had an influence on patients knowledge ( $\mathrm{P}=$ 0.003). Patients, who had diabetes for more than 10 years had better knowledge regarding its complications than patients, who had diabetes for less than 10 years $(P=0.008)$. Table 3 shows the details (Figure 2).

\subsection{Attitude Score}

The maximum attitude score was 13 . The mean score was 7.87 (95\% CI for mean 7.6 - 8.1) and standard deviation (SD) was \pm 2.76 with a range of 2 to 13 . Nearly $35 \%(n=146$; $34.4 \%$ ) of participants had a poor attitude regarding diabetic complications. About $23 \%(n=95)$ of the participants possessed a very good attitude level.

The majority of the respondents reported that they could prevent diabetic complications (66\%), and good glycemic control was one of the ways to prevent it (66.4\%). Only $45 \%$ of respondents agreed that regular blood glucose monitoring is helpful for preventing DM complications. Furthermore, $80 \%$ of the participants thought that smoking could exacerbate vascular complications due to diabetes while about 70\% agreed that exercising regularly was helpful in preventing complications. Most of the participants agreed that diabetic complications reduced life expectancy (69\%).

Age and gender of the respondents had a significant influence on attitude. Older age group $(\mathrm{P} \leq 0.001)$ and being a female $(\mathrm{P} \leq 0.001)$ was associated with a positive attitude. Married patients had better attitude score than unmarried patients $(\mathrm{P}=0.003)$. Patients with duration of diabetes more than 10 years had better attitude score than those who had duration of diabetes less than 10 years $(\mathrm{P} \leq$ 0.001) (Table 3).

\subsection{Practice Score}

The maximum practice score was 27 . The mean score was 16.89 (95\% CI for mean 16.25 to 17.53 ) and standard deviation (SD) was \pm 3.79 with a range of 3 to 27 . The finding was that nearly $20 \%(n=84 ; 19.8 \%)$ of the participants scored good in practice regarding diabetic complications. Almost 30\% ( $n=120 ; 28.2 \%$ ) of the participants possessed poor practice.

More than $95 \%(n=407 ; 95.8 \%)$ of the patients reported that they monitored their blood glucose on a regular basis 


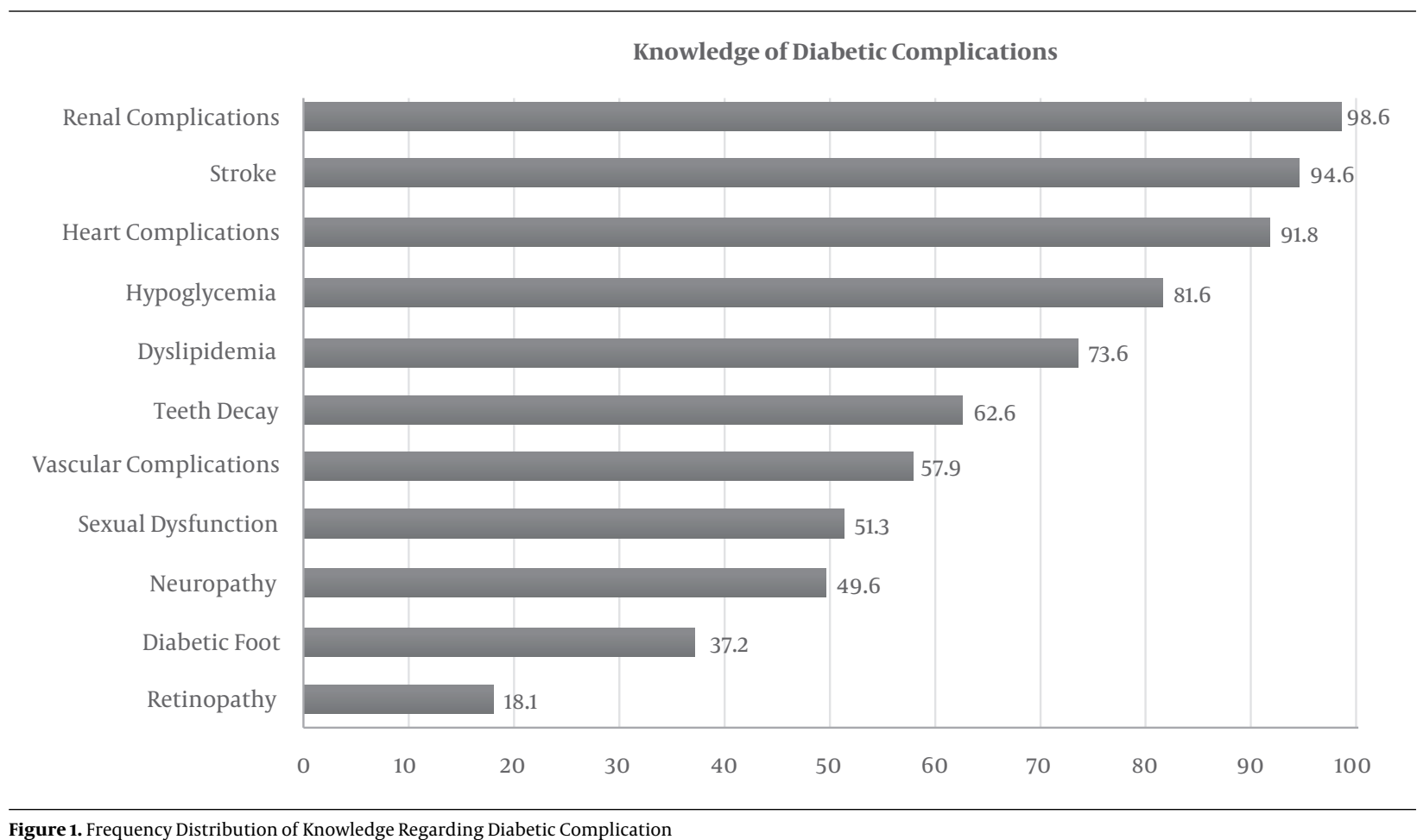

Figure 1. Frequency Distribution of Knowledge Regarding Diabetic Complication

Distribution (\%) of Knowledge, Attitude and Practices of Responents Respondents

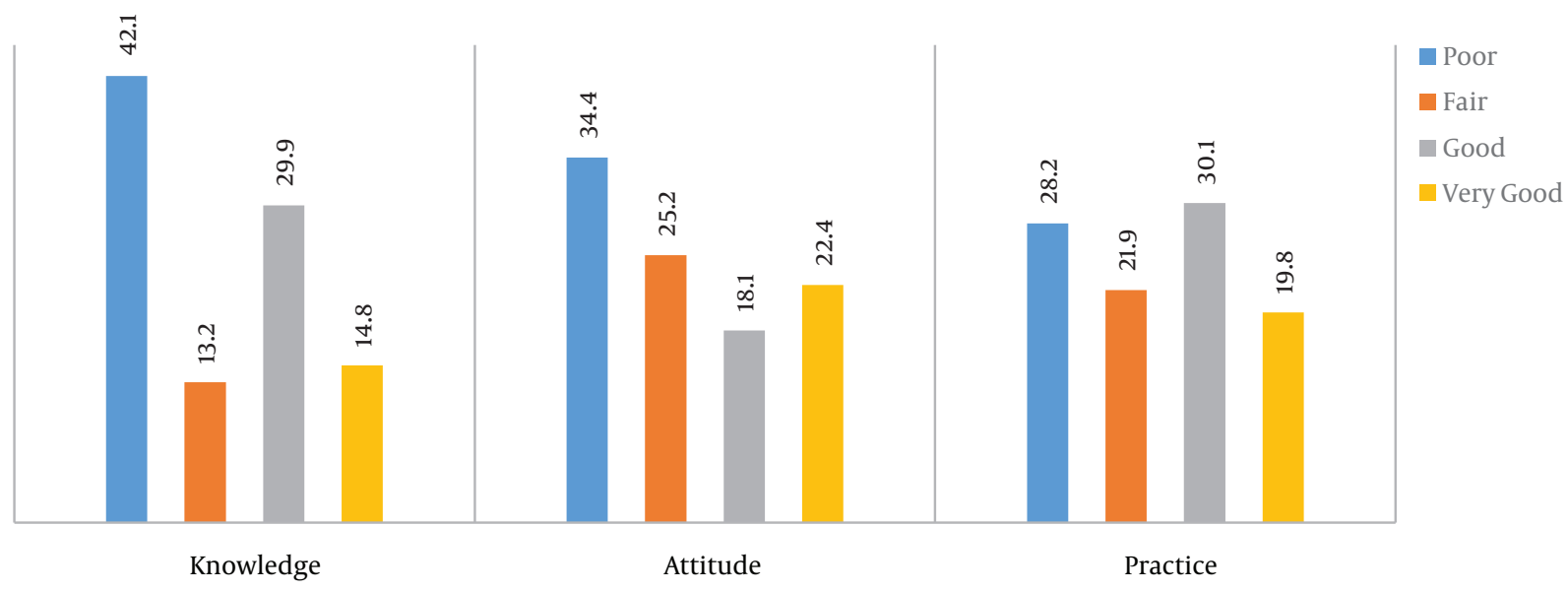

Figure 2. Percentage Distribution of Knowledge, Attitude and Practices of Survey Respondents

and more than $85 \%$ of patients followed their prescription regularly, yet only about $60 \%(n=243 ; 57.2 \%)$ performed exercise on a daily basis. Less than $50 \%$ of respondents reported about regular feet examination. Periodical kidney examination was done by approximately $64 \%(n=271$; $63.8 \%)$ of the respondents.
Practice score is also influenced by gender, habitat, marital status, and education. Unlike knowledge and attitude, mean score of practice was higher among males $(\mathrm{P} \leq 0.001)$. Similarly, mean score of practice was higher among married patients $(\mathrm{P}=0.001)$. Urban habitats had better practice score than semi-urban and rural habitats $(P$ 
$\leq$ 0.001). Family history of diabetes had a significant influence on patients practice score $(\mathrm{P} \leq 0.001)$ (Table 3$)$.

\subsection{Multivariable Analysis}

Multiple linear regression analysis showed that the predictors that influenced knowledge score were age, gender, education, occupation, socioeconomic status, and educational program. Keeping all other variables on the baseline, if age was increased by 1 year, the knowledge score was also increased by 0.04 (P value $<0.001)$. Females had better knowledge than males by 0.55 (P value 0.04). Controlling all other predictors, respondents with higher degrees had better knowledge score than illiterates (Pvalue 0.002). Respondents, who had attended the educational program had better knowledge than those who never attended by 1.49 (P value $<0.001$ )

Keeping all the variables on the baseline, one unit increase in knowledge score improved the attitude by 0.39 (P value $<0.001)$. Attitude score was improved by 0.07 with every year increase in age (P value $<0.001)$. Controlling all other predictors, females had a better attitude score by 1.24 than males (P value < 0.001). Attitude was better among those who attended the educational program than those who never attended by 1.99 (P value $<0.001$ ). Poor attitude level was noticed among respondents taking multiple treatment methods.

Marital status was a significant predicator for practice. Controlling other predictors, married respondents had good practice score than unmarried respondents (P value 0.017). Duration of diabetes mellitus (DM) (Years) was another significant influencing factor for practice. One year increase in the duration of DM improved practice score by 0.07 ( $P$ value 0.021 ). While other predictors were controlled, patients with family history of DM had better practice by 2.05 (P value < 0.001). Respondents attended the educational program regularly and had a lower practice score. Higher educated respondents had better practice score by 1.44 than illiterates (P value 0.045). Details are shown in Table 4.

\section{Discussion}

Several studies have been carried out on knowledge, attitude, and practices (KAP) of diabetes (18-22) or knowledge of complications of type 2 diabetes $(23,24)$. Similar studies have been conducted in Bangladesh (25-28). Therefore, no study was found assessing the Knowledge, Attitude and Practices (KAP) of diabetes complications among patients with type 2 diabetes. However, it was difficult to compare the current results with others.

Very few participants had good knowldege about diabetic complications, which is similar to others $(23,24)$.
The majority of the participants had a poor attitude level. The results showed that participants with better knowledge also had a better attitude score. In the practice section, only $30.1 \%$ were in good practice category. Those were a small number of patients, who were able to manage their health conditions to avoid further complications. These figures are supported by other similar studies (22).

In the current study, it is shown that nearly $81 \%$ of respondents knew diabetes could cause certain complicaitons if remained uncontrolled, while in another study it was only $51.1 \%$ and $59.6 \%$, respectively $(23,24)$. Cardiovascular (91.8\%), cerebrovascular (94.6\%), and renal complications (98.6\%) were known by most of the participants while eye complcations (18.1\%) were least known in this study. Similarity was found with other studies $(28,29)$. However, inadequate knowledge regarding complications of diabetes tend to decrease awareness and may lead to high economic burden in terms of management of complications.

The present study revealed that $66 \%$ of respondents agreed that they could prevent diabetic complications while in other studies the figure was 62.3 in Pakistan and 52.7 in Ethiopia $(18,22)$. In this study, almost $80 \%$ respondents had agreed that smoking can exacerbate diabetic foot complication, while another study reported that nearly half of the respondents were unware about smoking and its relationship with diabetic foot complications (24).

It is generally believed that males are more knowlegeable for healthy lifestyles than females. A study in Pakistan showed better knowledge level in males regarding diabetic complcaitions than females (30), yet the study of Haque et al. (2009) showed no significant difference in different genders (26). In the current study, keeping other predictors controlled, gender was a significant predictor of knowledge and attitude, where females scored better.

The present study found similarity with the study of Niroomand et al. (2015), in that age was associated with patient's knowledge, attitude, and practices regarding diabetes (31). In the current study, knowledge and attitude was improved with age. Hence, this may suggest that younger patients need greater motivation from their physician and family.

Good knowledge was significant among participants, who had higher socioeconomic status. This finding was consistent with other studies in India and Ethiopia $(20,32)$. This could be explained by the fact that participants with higher socioeconomic status have better access to education and alternative private checkups without waiting for conservative treatment facilities in the health system. In the current study, controlling other variables, educational status had a significant association with good knowledge, 
attitude, and practices. Other studies also led to the same findings $(20,22,33)$. This might be because educated participants are able to read necessary information easily compared to the illiterates.

In this study, the main source of information was health porofessinals (63.5\%), particuarly physicians. This statement was supported by a study in Ethiopia (20). This emphasizes on media contribution, which was very low in this study (10.6\%) compared to other studies in Gujarat, India (32). Consultation time given by doctors was less than five minutes, reported by nearly $17 \%$ of participants in the current study, which was better than India (43\%) and Ethiopia (58\%) $(20,32)$. Lack of information related to the disease persists. The explanation might be physician's focus on acute management rather than preventive care or heavy load of patients. Existing clinical evidence suggests that increasing community awareness regarding diabetes management is an ultimate tool for halting complications due to diabetes (34).

A recent study in Iran found a positive significant correlation between disease duration and complication with knowledge, attitude, and practice level (31). In the current study, duration of diabetes was a significant predictor of practice. This may be due to regular counseling and contact with health professionals. Another study in Iran, reported having had no effect of duration of diabetes with knowledge and practice regarding diabetes foot care, which may indicate the usefulness of patient education in healthcare facilities (24).

Attending an educational program was significantly associated with knowledge, attitude, and practices in the present study. Respondents, who attended educational programs performed better than those who never attended. It is important to know that providing education to vulnerable groups could become a cost-effective public health strategy (33) and properly designed educational programs could provide precise knowlege of diabetes even for less educated people (35).

Having positive family history of diabetes had a positive influence on patient's attitude and practice, though it was not associated with knowledge, which is in contrast with the findings of other studies (36). Receiving information from the family with chronic disease might influence the patient's attitude and daily practice, which can be a good source of information (31), yet, such informal sources are not always reliable.

This study could help in planning larger studies addressing the challenges in this project. As the current study was based on outpatients in one hospital, the results may not be typical of all diabetic patients in Bangladesh. The use of questionnaires for measuring knowledge, attitude, and practice areas could be another limitation because it is hard to avoid while assessing areas related to subjective fields of health, knowledge, choice, gratification, and identical areas bring risk of bias such that related with social desirability effect (37).

Evidence suggests that training and self-management is a core part of the treatment of diabetes (38). Patient education is the most constructive track that could assist with early detection, lessen the complications, and assist with the management of diabetes (39). This study reemphasized the fact that properly designed and implemented education and other support programs would be more fruitful for patients with diabetes. Provided complete information on patient's characteristics, healthcare professionals could effectively design their care processes, according to the patients' needs (40). Self-care is an effective way to reduce complications of diabetes (41).

\subsection{Conclusions}

Lack of knowledge, poor attitude, and poor practice level were found in this surveyed communinty, particularly in males, illieterates and low income groups. Younger age group and rural habitats need greater attention in educational campaigns and physicians counselling. Physicians active participation and time for providing structured education and counseling for patients may bring better therapeutic outcome and lessen complications. Self management of patients should be encouraged. Source of information collected in this study will help identify popular medium that should be strengthened for future awareness and provide an educational base for patients. The sources will also be helpful in dissemination of knowledge on the preventive aspects of diabetic complications.

\section{Acknowledgments}

The authors are grateful to the staff of the hospital for their cordial support and data collection and his team for collecting data within a limited time. Special thanks goes to all participants for their time, who enthusiastically took part in this study with patience.

\section{Footnote}

Financial Disclosure: The authors did not have any financial interest in any material of the manuscript.

\section{References}

1. Lozano R, Naghavi M, Foreman K, Lim S, Shibuya K, Aboyans V, et al. Global and regional mortality from 235 causes of death for 20 age groups in 1990 and 2010: a systematic analysis for the Global Burden of Disease Study 2010. Lancet. 2012;380(9859):2095-128. doi: 10.1016/S0140-6736(12)61728-0. [PubMed: 23245604]. 
2. Murray CJ, Vos T, Lozano R, Naghavi M, Flaxman AD, Michaud C, et al. Disability-adjusted life years (DALYs) for 291 diseases and injuries in 21 regions, 1990-2010: a systematic analysis for the Global Burden of Disease Study 2010. Lancet. 2012;380(9859):2197-223. doi: 10.1016/S01406736(12)61689-4. [PubMed: 23245608].

3. WHO . Mortality Database. Geneva: World Health Organization; 2016.

4. World Health Organization . Global health estimates: Deaths by cause, age, sex and country. Geneva: WHO; 2012.

5. Saquib N, Saquib J, Ahmed T, Khanam MA, Cullen MR. Cardiovascular diseases and type 2 diabetes in Bangladesh: a systematic review and meta-analysis of studies between 1995 and 2010. BMC Public Health. 2012;12:434. doi: 10.1186/1471-2458-12-434. [PubMed: 22694854].

6. Hussain A, Rahim MA, Azad Khan AK, Ali SM, Vaaler S. Type 2 diabetes in rural and urban population: diverse prevalence and associated risk factors in Bangladesh. Diabet Med. 2005;22(7):931-6. doi: 10.1111/j.14645491.2005.01558.x. [PubMed: 15975110].

7. Sayeed MA, Mahtab H, Akter Khanam P, Abdul Latif Z, Keramat Ali SM, Banu A, et al. Diabetes and impaired fasting glycemia in a rural population of Bangladesh. Diabetes Care. 2003;26(4):1034-9. [PubMed: 12663569].

8. IDF. IDF Diabetes Atlas 7th Edition. International Diabetes Federation (IDF) 2015. Available from: http://www.diabetesatlas.org.

9. Liu Z, Fu C, Wang W, Xu B. Prevalence of chronic complications of type 2 diabetes mellitus in outpatients - a cross-sectional hospital based survey in urban China. Health Qual Life Outcomes. 2010;8:62. doi: 10.1186/1477-7525-8-62. [PubMed: 20579389].

10. Goodman G, Hardman J, Limbird L, Goodman GA. Insulin, Oral Hypoglycaemic agents and the pharmacology of endocrine pancreas. Pharmacol Basis Ther. 2006;60:1686-710.

11. Vijan S, Stevens DL, Herman WH, Funnell MM, Standiford CJ. Screening, prevention, counseling, and treatment for the complications of type II diabetes mellitus. Putting evidence into practice.J Gen Intern Med. 1997;12(9):567-80. [PubMed: 9294791].

12. Eastman RC, Javitt JC, Herman WH, Dasbach EJ, Copley-Merriman C, Maier W, et al. Model of complications of NIDDM. II. Analysis of the health benefits and cost-effectiveness of treating NIDDM with the goal of normoglycemia. Diabetes Care. 1997;20(5):735-44. [PubMed: 9135935].

13. Wee HL, Ho HK, Li SC. Public awareness of diabetes mellitus in Singapore. Singapore Med J. 2002;43(3):128-34. [PubMed:12005338].

14. Larsson D, Lager IPMN, Larsson D, Lager I, Nilsson PM. Diabetes Mellitus. Scand J Public Health. 1999;2:101-5.

15. US Public Health Service. The prevention and treatment of complications of diabetes. A guide for primary care practitioners. Centres for Disease Control; 1991.

16. Kirigia JM, Sambo HB, Sambo LG, Barry SP. Economic burden of diabetes mellitus in the WHO African region. BMC Int Health Hum Rights. 2009;9:6. doi: 10.1186/1472-698X-9-6. [PubMed: 19335903].

17. Roglic G, Unwin N, Bennett PH, Mathers C, Tuomilehto J, Nag S, et al. The burden of mortality attributable to diabetes: realistic estimates for the year 2000. Diabetes Care. 2005;28(9):2130-5. [PubMed: 16123478].

18. Pardhan S, Mahomed I. Knowledge, self-help and socioeconomic factors in South Asian and Caucasian diabetic patients. Eye (Lond). 2004;18(5):509-13. doi: 10.1038/sj.eye.6700680. [PubMed: 15131683].

19. Adil MM, Alam AY, Jaffery T. Knowledge of type 2 diabetic patients about their illness: pilot project. J Pak Med Assoc. 2005;55(5):221-4. [PubMed: 15960293].

20. Feleke SA. Assessment of the Level and Associated Factors with Knowledge and Practice of Diabetes Mellitus among Diabetic Patients Attending at FelegeHiwot Hospital, Northwest Ethiopia. Clin Med Res. 2013;2(6):110. doi: 10.11648/j.cmr.20130206.11.

21. Mathew A, Jacob N, Jose S, P R, K S, R S, et al. Knowledge about risk factors, symptoms and complications of diabetes among adults in South India. Int JMed Sci Public Health. 2014;3(9):1086. doi:10.5455/ijmsph.2014.190620143.
22. Islam FM, Chakrabarti R, Dirani M, Islam MT, Ormsby G, Wahab $\mathrm{M}$, et al. Knowledge, attitudes and practice of diabetes in rural Bangladesh: the Bangladesh Population based Diabetes and Eye Study (BPDES). PLoS One. 2014;9(10):e110368. doi: 10.1371/journal.pone.0110368. [PubMed: 25313643].

23. Saleh F, Mumu SJ, Ara F, Begum HA, Ali L. Knowledge and self-care practices regarding diabetes among newly diagnosed type 2 diabetics in Bangladesh: a cross-sectional study. BMC Public Health. 2012;12:1112. doi: 10.1186/1471-2458-12-1112. [PubMed: 23267675].

24. Khamseh ME, Vatankhah N, Baradaran HR. Knowledge and practice of foot care in Iranian people with type 2 diabetes. Int Wound J. 2007;4(4):298-302. doi: 10.1111/j.1742-481X.2007.00381.x. [PubMed: 18154624].

25. Saleh F, Mumu SJ, Afnan F, Ali L, Chaudhury HS, Akhter A, et al. Knowledge, Attitude And Practice Of Hypercholesterolemic Type 2 Diabetic Subjects On Dyslipidemia. Ibrahim Med College J. 2011;5(2):37-41.

26. Hoque MA, Islam MS, Khan MAM, Ahasan HAMN. Knowledge of Diabetic Complications in a Diabetic Population. J Med. 2009;10(2) doi: 10.3329/jom.v10i2.2821.

27. Ullah F, Afridi AK, Rahim F, Ashfaq M, Khan S, Shabbier G, et al. Knowledge of Diabetic Complications in Patients with Diabetes Mellitus. J Ayub Med Coll Abbottabad. 2015;27(2):360-3. [PubMed: 26411116].

28. O'Sullivan EP, Bhargava A, O'Callaghan M, Buckley U, De Faoite T, Moynihan K, et al. Awareness of diabetes complications in an Irish population. Ir J Med Sci. 2009;178(4):401-6. doi: 10.1007/s11845-0090301-0. [PubMed: 19259760].

29. Hawthorne K, Tomlinson S. Pakistani moslems with Type 2 diabetes mellitus: effect of sex, literacy skills, known diabetic complications and place of care on diabetic knowledge, reported self-monitoring management and glycaemic control. Diabet Med. 1999;16(7):591-7. [PubMed: 10445836].

30. Nisar N, Khan IA, Qadri MH, Sher SA. Knowledge and risk assessment of diabetes mellitus at primary care level: a preventive approach required combating the disease in a developing country. PakJ Med Sci. 2008;24(5):667-72.

31. Niroomand M, Ghasemi SN, Karimi-Sari H, Kazempour-Ardebili S, Amiri P, Khosravi MH. Diabetes knowledge, attitude and practice (KAP) study among Iranian in-patients with type-2 diabetes: A crosssectional study. Diabetes Metab Syndr. 2016;10(1 Suppl 1):S114-9. doi: 10.1016/j.dsx.2015.10.006. [PubMed: 26610404].

32. Shah VN, Kamdar PK, Shah N. Assessing the knowledge, attitudes and practice of type 2 diabetes among patients of Saurashtra region, $\mathrm{Gu}$ jarat. Int J Diabetes Dev Ctries. 2009;29(3):118-22. doi: 10.4103/09733930.54288. [PubMed: 20165648].

33. Balagopal P, Kamalamma N, Patel TG, Misra R. A community-based diabetes prevention and management education program in a rural village in India. Diabetes Care. 2008;31(6):1097-104.

34. Memon MS, Shaikh SA, Shaikh AR, Fahim MF, N. Mumtaz S, Ahmed $\mathrm{N}$. An assessment of knowledge, attitude and practices (KAP) towards diabetes and diabetic retinopathy in a suburban town of Karachi. Pak J Med Sci. 2015;31(1):183-8. doi: 10.12669/pjms.311.6317. [PubMed: 25878640].

35. Otero LM, Zanetti ML, Ogrizio MD. Knowledge of diabetic patients about their disease before and after implementing a diabetes education program. Rev Lat Am Enfermagem. 2008;16(2):231-7. [PubMed: 18506341].

36. Al-Maskari F, El-Sadig M, Al-Kaabi JM, Afandi B, Nagelkerke N, Yeatts KB. Knowledge, attitude and practices of diabetic patients in the United Arab Emirates. PLoS One. 2013;8(1):e52857. doi: 10.1371/journal.pone.0052857. [PubMed: 23341913].

37. Sjostrom O, Holst D. Validity of a questionnaire survey: response patterns in different subgroups and the effect of social desirability. Acta Odontol Scand. 2002;60(3):136-40. [PubMed:12166905].

38. Sousa VD, Zauszniewski JA. Toward a theory of diabetes self-care management. J Theory Construct Test. 2005;9(2):61. 
39. Mazzuca SA, Moorman NH, Wheeler ML, Norton JA, Fineberg NS, Vinicor F, et al. The diabetes education study: a controlled trial of the effects of diabetes patient education. Diabetes Care. 1986;9(1):1-10. [PubMed: 3948638].

40. Gafvels C, Lithner F, Borjeson B. Living with diabetes: relationship to gender, duration and complications. A survey in northern Sweden. Di- abet Med. 1993;10(8):768-73. [PubMed: 8261761].

41. Heisler M, Piette JD, Spencer M, Kieffer E, Vijan S. The relationship between knowledge of recent HbA1c values and diabetes care understanding and self-management. Diabetes Care. 2005;28(4):816-22. [PubMed: 15793179]. 
Table 1. Characteristics of Study Respondents $(n=425)$

\begin{tabular}{|c|c|}
\hline Characteristics & Values $^{\mathrm{a}}$ \\
\hline Age, $y$ & $43.45 \pm 11.81$ \\
\hline$\leq 25$ & $17(4)$ \\
\hline $26-45$ & $231(54.4)$ \\
\hline $46-65$ & $156(36.7)$ \\
\hline$>65$ & $21(4.9)$ \\
\hline \multicolumn{2}{|l|}{ Gender } \\
\hline Male & $234(55.1)$ \\
\hline Female & $191(44.9)$ \\
\hline \multicolumn{2}{|l|}{ Marital status } \\
\hline Married & $366(86.1)$ \\
\hline Unmarried & $59(13.9)$ \\
\hline \multicolumn{2}{|l|}{ Habitat } \\
\hline Urban & $190(44.7)$ \\
\hline Semi-urban & $161(37.9)$ \\
\hline Rural & $74(17.4)$ \\
\hline \multicolumn{2}{|l|}{ Education } \\
\hline Illiterate & $30(7.1)$ \\
\hline Primary to 8th grade & $93(21.9)$ \\
\hline Secondary & $71(16.7)$ \\
\hline Higher secondary & $122(28.7)$ \\
\hline Graduate and above & $109(25.6)$ \\
\hline \multicolumn{2}{|l|}{ Occupation } \\
\hline Unemployed/laborer/retired & $43(10.1)$ \\
\hline Housewife & $125(29.4)$ \\
\hline Government services & $65(15.3)$ \\
\hline Private sector & $87(20.5)$ \\
\hline Business & $105(24.7)$ \\
\hline \multicolumn{2}{|l|}{ Socio-economic status } \\
\hline Low income & $145(34.1)$ \\
\hline Average income & $140(32.9)$ \\
\hline Rich & $140(32.9)$ \\
\hline Duration of diabetes, $y$ & $9.16 \pm 6.03$ \\
\hline$<5$ & $92(21.6)$ \\
\hline $5-10$ & $204(48.0)$ \\
\hline$>10$ & $129(30.4)$ \\
\hline \multicolumn{2}{|l|}{ Family history of diabetes } \\
\hline Yes & $174(40.9)$ \\
\hline No & $137(32.2)$ \\
\hline Unkonwn & $114(26.8)$ \\
\hline
\end{tabular}




\begin{tabular}{|c|c|}
\hline \multicolumn{2}{|l|}{ Educational programs } \\
\hline Attended once & $164(38.6)$ \\
\hline Attended regularly & $104(24.5)$ \\
\hline Never attended & $157(36.9)$ \\
\hline \multicolumn{2}{|l|}{ Consultation Time, min } \\
\hline$<5$ & $70(16.5)$ \\
\hline $5-10$ & $150(58.8)$ \\
\hline$>10$ & $105(24.7)$ \\
\hline \multicolumn{2}{|l|}{ Methods of treatment } \\
\hline Diet + Oral agents & $68(16)$ \\
\hline Diet + Insulin & $204(48)$ \\
\hline Diet + Oral agents + Insulin & $150(35.3)$ \\
\hline None & $3(0.7)$ \\
\hline \multicolumn{2}{|l|}{ Use of herbal medication } \\
\hline Yes & $112(26.4)$ \\
\hline No & $313(73.6)$ \\
\hline \multicolumn{2}{|l|}{ Monitoring blood glucose } \\
\hline Self monitoring & $16(3.8)$ \\
\hline Local pharmacy & $112(26.4)$ \\
\hline Hospital & $297(69.9)$ \\
\hline
\end{tabular}

${ }^{\mathrm{a}}$ Values are expressed as mean $\pm \mathrm{SD}$ or $\mathrm{n}$. (\%). 
Table 3. Bivariate Analysis for Knowledge, Attitude and Practices Regarding Diabetic Complications ${ }^{\mathrm{a}}$

\begin{tabular}{|c|c|c|c|c|c|c|}
\hline \multirow[t]{2}{*}{ Variables } & \multicolumn{2}{|c|}{ Knowledge } & \multicolumn{2}{|c|}{ Attitude } & \multicolumn{2}{|c|}{ Practice } \\
\hline & Mean \pm SD & P Value & Mean \pm SD & P Value & Mean \pm SD & PValue \\
\hline Age, $y$ & & $<0.00$ & & $<0.001$ & & 0.368 \\
\hline$\leq 25$ & $7.47 \pm 1.41$ & & $5.41 \pm 1.50$ & & $15.88 \pm 2.26$ & \\
\hline $26-45$ & $8.80 \pm 1.97$ & & $7.19 \pm 2.44$ & & $16.95 \pm 3.82$ & \\
\hline $46-65$ & $9.86 \pm 2.13$ & & $9.02 \pm 2.82$ & & $16.91 \pm 3.79$ & \\
\hline$>65$ & $9.85 \pm 2.26$ & & $8.71 \pm 2.75$ & & $16.85 \pm 4.49$ & \\
\hline Gender & & 0.004 & & $<0.001$ & & $<0.001$ \\
\hline Male & $8.92 \pm 2.10$ & & $7.11 \pm 2.40$ & & $17.48 \pm 3.67$ & \\
\hline Female & $9.58 \pm 2.08$ & & $8.79 \pm 2.88$ & & $16.16 \pm 3.81$ & \\
\hline Marital status & & 0.094 & & 0.003 & & 0.001 \\
\hline Married & $9.25 \pm 2.12$ & & $8.02 \pm 2.82$ & & $17.13 \pm 3.88$ & \\
\hline Unmarried & $8.76 \pm 2.03$ & & $6.89 \pm 2.89$ & & $15.38 \pm 2.12$ & \\
\hline Habitat & & 0.022 & & 0.155 & & $<0.001$ \\
\hline Urban & $9.18 \pm 2.17$ & & $8.01 \pm 2.76$ & & $17.53 \pm 3.71$ & \\
\hline Semi-urban & $9.49 \pm 2.12$ & & $7.95 \pm 2.98$ & & $15.98 \pm 3.07$ & \\
\hline Rural & $8.54 \pm 1.79$ & & $7.31 \pm 2.13$ & & $17.21 \pm 4.82$ & \\
\hline Education & & $<0.001$ & & $<0.001$ & & 0.001 \\
\hline Illiterate & $7.93 \pm 1.63$ & & $6.26 \pm 1.33$ & & $17.56 \pm 3.48$ & \\
\hline Primary to 8 th grade & $8.59 \pm 1.66$ & & $7.04 \pm 1.88$ & & $16.95 \pm 4.44$ & \\
\hline Secondary & $8.87 \pm 1.82$ & & $8.23 \pm 2.77$ & & $16.15 \pm 3.80$ & \\
\hline Higher secondary & $9.62 \pm 2.12$ & & $8.39 \pm 2.99$ & & $16.08 \pm 3.08$ & \\
\hline Graduate and above & $9.77 \pm 2.38$ & & $8.19 \pm 3.09$ & & $18.03 \pm 3.45$ & \\
\hline Occupation & & 0.018 & & $<0.001$ & & 0.087 \\
\hline Unemployed/laborer/retired & $9.20 \pm 2.25$ & & $7.76 \pm 2.66$ & & $17.58 \pm 3.61$ & \\
\hline Housewife & $9.12 \pm 1.94$ & & $8.29 \pm 2.66$ & & $16.33 \pm 4.06$ & \\
\hline Government services & $9.15 \pm 2.40$ & & $7.30 \pm 2.86$ & & $17.15 \pm 3.56$ & \\
\hline Private sector & $9.81 \pm 2.04$ & & $8.78 \pm 3.03$ & & $16.44 \pm 3.69$ & \\
\hline Business & $8.77 \pm 2.04$ & & $7.00 \pm 2.28$ & & $17.47 \pm 3.66$ & \\
\hline Socio-economic status & & 0.003 & & 0.460 & & 0.064 \\
\hline Low income & $9.07 \pm 1.93$ & & $7.95 \pm 2.67$ & & $16.40 \pm 3.88$ & \\
\hline Average income & $8.82 \pm 2.14$ & & $7.63 \pm 2.70$ & & $16.84 \pm 3.91$ & \\
\hline Rich & $9.67 \pm 2.19$ & & $8.02 \pm 2.90$ & & $17.45 \pm 3.91$ & \\
\hline Duration of diabetes, $y$ & & 0.008 & & $<0.001$ & & 0.089 \\
\hline$<5$ & $8.79 \pm 1.80$ & & $7.15 \pm 2.53$ & & $16.98 \pm 3.87$ & \\
\hline $5-10$ & $9.08 \pm 2.13$ & & $7.68 \pm 2.78$ & & $16.50 \pm 3.53$ & \\
\hline$>10$ & $9.64 \pm 2.23$ & & $8.72 \pm 2.68$ & & $17.43 \pm 4.07$ & \\
\hline Family history of diabetes & & 0.401 & & 0.137 & & $<0.001$ \\
\hline Yes & $9.25 \pm 2.08$ & & $7.85 \pm 2.61$ & & $17.54 \pm 3.96$ & \\
\hline No & $8.99 \pm 2.13$ & & $8.19 \pm 2.71$ & & $17.26 \pm 3.62$ & \\
\hline
\end{tabular}




\begin{tabular}{|c|c|c|c|c|c|c|}
\hline Unkown & $9.32 \pm 2.13$ & & $7.50 \pm 2.99$ & & $15.44 \pm 3.34$ & \\
\hline Educational programs Attended once & $10.23 \pm 1.95$ & $<0.001$ & $9.56 \pm 2.96$ & $<0.001$ & $15.73 \pm 3.11$ & $<0.001$ \\
\hline Attended regularly & $9.25 \pm 2.25$ & & $7.22 \pm 2.44$ & & $16.67 \pm 3.36$ & \\
\hline Never attended & $8.05 \pm 1.53$ & & $6.53 \pm 1.53$ & & $18.24 \pm 4.25$ & \\
\hline Consultation time, $\min$ & $9.40 \pm 1.92$ & $<0.001$ & $8.52 \pm 2.78$ & $<0.001$ & $15.74 \pm 3.89$ & 0.005 \\
\hline \multicolumn{7}{|l|}{$<5$} \\
\hline 5 -10 minutes & $9.48 \pm 2.12$ & & $8.28 \pm 2.90$ & & $16.90 \pm 3.83$ & \\
\hline$>10$ minutes & $8.34 \pm 1.99$ & & $6.43 \pm 1.73$ & & $17.62 \pm 3.43$ & \\
\hline Methods of treatment & & 0.299 & & 0.026 & & 0.070 \\
\hline Diet + Oral agents & $8.88 \pm 1.92$ & & $8.08 \pm 2.71$ & & $17.66 \pm 4.26$ & \\
\hline Diet + Insulin & $9.11 \pm 2.05$ & & $7.58 \pm 2.70$ & & $16.85 \pm 3.71$ & \\
\hline Diet + Oral agents + Insulin & $9.43 \pm 2.07$ & & $8.08 \pm 2.81$ & & $16.67 \pm 3.63$ & \\
\hline None & $9.00 \pm 2.00$ & & $11.66 \pm 0.57$ & & $12.66 \pm 1.15$ & \\
\hline Use of herbal medication & & 0.001 & & $<0.001$ & & 0.370 \\
\hline Yes & $8.61 \pm 1.86$ & & $6.78 \pm 1.89$ & & $16.61 \pm 4.02$ & \\
\hline No & $9.39 \pm 2.16$ & & $8.25 \pm 2.91$ & & $16.99 \pm 3.70$ & \\
\hline Monitoring blood glucose & & $<0.001$ & & $<0.001$ & & 0.999 \\
\hline Self monitoring & $10.68 \pm 2.30$ & & $7.75 \pm 3.45$ & & $16.93 \pm 3.58$ & \\
\hline Local pharmacy & $8.52 \pm 2.06$ & & $6.50 \pm 2.16$ & & $16.89 \pm 3.34$ & \\
\hline Hospital & $9.36 \pm 2.05$ & & $8.39 \pm 2.15$ & & $16.88 \pm 3.96$ & \\
\hline
\end{tabular}

Abbreviation: SD, standard deviation.

${ }^{\mathrm{a}} \mathrm{P} \leq 0.05$ is significant. 
Table 4. Multivariable Analysis for Knowledge, Attitude and Practices

\begin{tabular}{|c|c|c|c|c|c|c|c|c|c|}
\hline Predictors & \multicolumn{3}{|c|}{ Knowledge } & \multicolumn{3}{|c|}{ Attitude } & \multicolumn{3}{|c|}{ Practice } \\
\hline & \multirow[t]{2}{*}{ Coef. } & \multicolumn{2}{|c|}{$95 \% \mathrm{CI}$} & \multirow[t]{2}{*}{ Coef. } & \multicolumn{2}{|c|}{$95 \% \mathrm{CI}$} & \multirow[t]{2}{*}{ Coef. } & \multicolumn{2}{|c|}{$95 \% \mathrm{CI}$} \\
\hline & & Lower & Upper & & Lower & Upper & & Lower & Upper \\
\hline Age & $0.04^{\mathrm{a}}$ & 0.03 & 0.06 & $0.07^{\mathrm{a}}$ & 0.05 & 0.08 & . & - & - \\
\hline \multicolumn{10}{|l|}{ Sex } \\
\hline Male & & ference & & & ference & & & . & \\
\hline Female & $0.55^{b}$ & 0.21 & 1.12 & $1.24^{\mathrm{a}}$ & 0.83 & 1.65 & - & $\cdot$ & - \\
\hline \multicolumn{10}{|l|}{ Education } \\
\hline Illiterate & & ference & & & ference & & & Reference & \\
\hline Primary to 8th grade & 0.62 & -0.16 & 1.39 & 0.29 & -0.50 & 1.10 & 0.09 & -1.31 & 1.49 \\
\hline Secondary & 0.67 & -0.15 & 1.49 & $1.29^{\mathrm{b}}$ & 0.26 & 1.92 & -0.53 & -2.00 & 0.94 \\
\hline Higher secondary & $1.22^{\mathrm{b}}$ & 0.44 & 1.99 & $1.08^{\mathrm{b}}$ & 0.28 & 1.89 & -0.04 & -1.44 & 1.35 \\
\hline Graduate and above & $1.27^{\mathrm{b}}$ & 0.45 & 2.09 & 0.77 & -0.03 & 1.58 & $1.44^{\mathrm{b}}$ & 0.03 & 2.85 \\
\hline \multicolumn{10}{|l|}{ Occupation } \\
\hline Unemployed/retired & & ference & & & . & 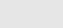 & & - & \\
\hline Housewife & -0.01 & -0.82 & 0.79 & - & - & - & - & - & - \\
\hline Government service & 0.04 & -0.74 & 0.82 & . & - & . & - & - & - \\
\hline Private sector & 0.59 & -0.18 & 1.37 & - & . & - & - & - & - \\
\hline Business & 0.46 & -0.28 & 1.21 & . & . & . & . & . & . \\
\hline Socio-economic status & & ference & & & - & & & - & \\
\hline Low income & & & & 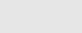 & & . & 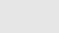 & . & 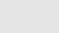 \\
\hline Average income & -0.15 & -0.60 & 0.29 & - & - & - & - & $\cdot$ & . \\
\hline Rich & $0.51^{\mathrm{b}}$ & 0.03 & 0.98 & - & . & - & . & - & - \\
\hline \multicolumn{10}{|l|}{ Educational programs } \\
\hline Never attended & Reference & & & Reference & & & & Reference & \\
\hline Attended once & $1.49^{\mathrm{a}}$ & 1.05 & 1.95 & $1.33^{\mathrm{a}}$ & 0.84 & 1.83 & $1.95^{\mathrm{a}}$ & -2.83 & -1.07 \\
\hline Attended regularly & $1.05^{\mathrm{a}}$ & 0.59 & 1.50 & 0.19 & -0.32 & 0.72 & $-1.57^{c}$ & -2.54 & -0.69 \\
\hline \multicolumn{10}{|l|}{ Consultation time, min } \\
\hline$<5$ & & ference & & & - & & & - & \\
\hline $5-10$ & 0.01 & -0.49 & 0.50 & - & - & - & . & - & - \\
\hline$>10$ & -0.36 & -0.96 & 0.24 & - & . & - & . & - & - \\
\hline \multicolumn{10}{|l|}{ Monitoring blood glucose } \\
\hline Self monitoring & & ference & & & ference & & 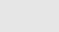 & . & 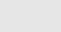 \\
\hline Local pharmacy & $-1.55^{\mathrm{c}}$ & -2.48 & -0.61 & 0.33 & -0.69 & 1.36 & - & - & - \\
\hline Hospital & $-1.09^{b}$ & -2.01 & -0.19 & $1.08^{\mathrm{b}}$ & 0.09 & 2.05 & . & - & - \\
\hline \multicolumn{10}{|l|}{ Family history of diabetes } \\
\hline Unknown & & - & & & ference & & & Reference & \\
\hline Yes & - & - & - & $0.97^{\mathrm{a}}$ & -1.48 & -0.46 & $2.05^{\mathrm{a}}$ & -2.92 & -1.18 \\
\hline No & - & - & . & $-0.58^{\mathrm{b}}$ & -1.03 & -0.14 & 0.22 & -0.55 & 1.00 \\
\hline \multicolumn{10}{|l|}{ Methods of treatment } \\
\hline None & & - & & & ference & & & - & \\
\hline Diet + Oral agents & - & - & - & $-3.45^{\mathrm{c}}$ & -5.69 & -1.19 & - & - & - \\
\hline Diet + Insulin & - & - & - & $3.89^{\mathrm{a}}$ & -6.11 & -1.69 & . & - & . \\
\hline Diet + Oralagents + Insulin & - & - & - & $4.06^{\mathrm{a}}$ & -6.28 & -1.84 & - & - & - \\
\hline Marital status & & & & & & & & & \\
\hline Married & & . & & & - & & & Reference & \\
\hline Unmarried & - & . & . & . & . & . & $-1.21^{\mathrm{b}}$ & -2.19 & -0.21 \\
\hline Duration of diabetes & - & - & - & - & . & - & $0.07^{\mathrm{b}}$ & 0.01 & 0.13 \\
\hline Knowledge score & & $\mathrm{N} / \mathrm{A}$ & & $0.39^{\mathrm{a}}$ & 0.29 & 0.50 & -0.17 & -0.36 & 0.02 \\
\hline Attitude score & & $\mathrm{N} / \mathrm{A}$ & & & $\mathrm{N} / \mathrm{A}$ & & $-0.19^{\mathrm{b}}$ & -0.34 & -0.04 \\
\hline Constant & 5.85 & 4.25 & 7.44 & 1.81 & -0.98 & 4.59 & 22.03 & 19.74 & 24.32 \\
\hline Adjusted $\mathrm{R}^{2}$ & & 0.324 & & & 0.52 & & & 0.23 & \\
\hline
\end{tabular}

Abbreviations: Cl, confidence interval; Coef,, coefficient.

$\mathrm{a}<0.0001$
$\mathrm{~b}<0.05$.

c $<0.001$.

Int J Endocrinol Metab. 2017; 15(3):e12555. 